\title{
Influence of hyperaldosteronism upon gastric secretion $^{1}$
}

\author{
R. M. BADDELEY, JANICE EVANS, AND J. A. GRIFFIN \\ From the Department of Surgery, Queen Elizabeth Hospital, Edgbaston, Birmingham
}

Cirrhotic ascites, in which secondary hyperaldosteronism is a notable feature, is associated with impaired gastric secretion (Baddeley, 1968). Obstruction to hepatic venous outflow, which also induces secondary hyperaldosteronism and ascites (Orloff, Ross, Baddeley, Nutting, Spitz, Sloop, Neesby, and Halasz, 1964), depresses acid secretion from Heidenhain pouches in dogs with cirrhotic and non-cirrhotic livers (Baddeley, Nutting, Ross, Sloop, Halasz, and Orloff, 1964; Baddeley, 1968). For these reasons an investigation of the influence of aldosterone upon gastric secretion was carried out.

\section{EXPERIMENTAL METHODS}

Heidenhain pouches were constructed in eight bitches and three months allowed for convalescence. In acute studies submaximally stimulated gastric secretion was induced by the continous intravenous infusion of histamine acid phosphate $(0.5 \mu \mathrm{g} / \mathrm{kg} /$ minute) over a period of four or five hours and the secretion of the last hour was compared with that of the second. In half the studies d-aldosterone was added to the infusate after two hours in dosages of $0.02,0.5$, or $1.1 \mathrm{mg}$ per hour. Its presence in solution was confirmed spectrophotometrically (Weast, 1964) on all occasions and, in two dogs, by observation of its renal sodium-retaining and potassiumlosing effects.

In the chronic studies the dogs were fed a standard meat diet. Continuous daily collections of the Heidenhain pouch secretions were divided into six-hour post-cibal and 18-hour 'basal' specimens, the latter representing the end of the intestinal phase of gastric secretion as well as the true basal output. Control values were obtained over 21 days and similarly during 21 daily intramuscular injections of $2.5 \mathrm{mg}$ d-aldosterone monoacetate in oil. This dosage was based on direct measurements of aldosterone secretion in experimental ascites (Orloff et al, 1964). Serum electrolytes, blood volume, and body weight were measured twice weekly.

\section{RESULTS}

ACUTE STUDIES In the acute studies seven dogs were subjected each to a minimum of eight studies. The

'Based upon a communication to the Surgical Research Society, Aberdeen, July, 1967. mean percentage changes observed are summarized in Figure 1. There was very little difference between the influence of histamine alone and of histamine plus aldosterone on volume and output of acid and pepsin from the second to the fourth or fifth hours of infusions with any of the aldosterone dosages used.

The electrolyte content of gastric secretion showed a decline in $\mathrm{Na}^{+}$secretion, greater under the influence of aldosterone than with histamine alone in six dogs $(P<0.01)$, the seventh showing no change. Overall, $\mathrm{Na}^{+}$secretion fell from $-2 \cdot 1 \%$ with histamine alone to $-13.1 \%$ with histamine plus aldosterone $(\mathrm{P}<$ $0.05)$. Secretion of $\mathrm{K}^{+}$showed no significant change and decline in the $\mathrm{Na}^{+}: \mathrm{K}^{+}$ratios showed no effect attributable to aldosterone.

CHRONIC STUDIES (Fig. 2) There was considerable variation from dog to dog regarding 'basal', postcibal, and total daily secretion of acid and pepsin and no statistically significant change attributable to a state of hyperaldosteronism was observed. Furthermore, hyperaldosteronism did not have a significant effect upon sodium or potassium secretion.

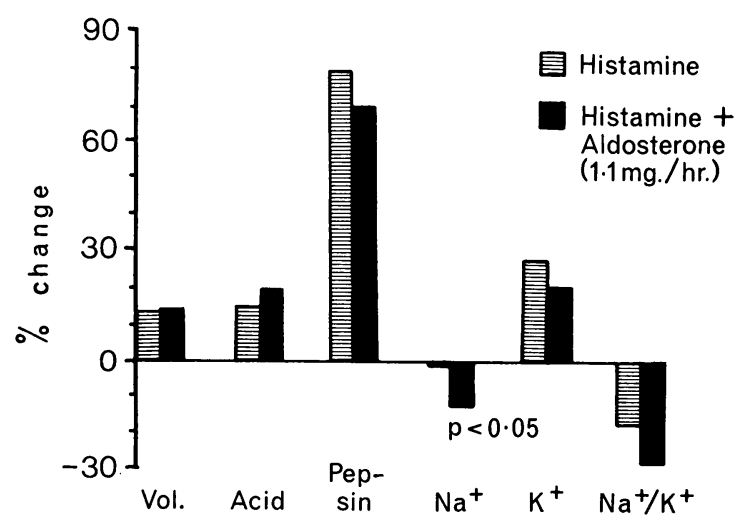

FIG. 1. Changes in gastric secretion from the second to the fourth hours of four-hour submaximal intravenous infusions of histamine and histamine plus aldosterone. 


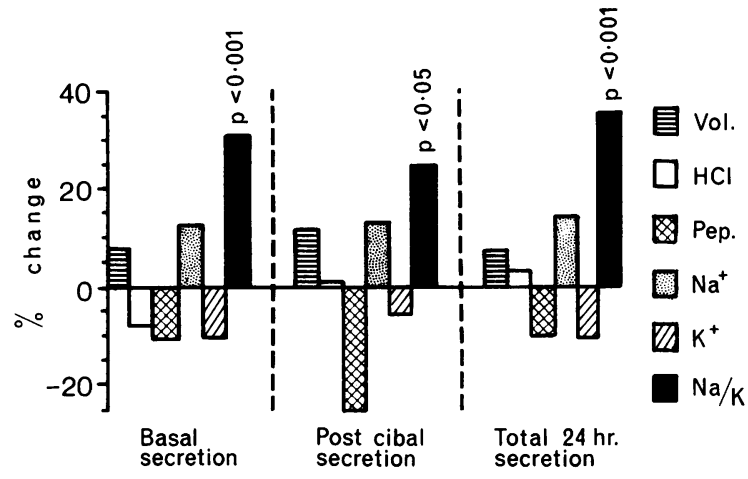

FIG. 2. Experimental chronic hyperaldosteronism. Mean percentage change in daily secretion from Heidenhain pouches in five dogs.

However, because there was a tendency for sodium secretion to increase and for potassium secretion to decrease the $\mathrm{Na}^{+}: \mathrm{K}^{+}$ratio for 'basal', post-cibal, and total daily secretion all increased significantly (P $<0.05$ to $<0.001$ ).

The potency of the aldosterone injections was confirmed by increases in blood volume $(\mathrm{P}<0.01)$ and body weight, and falls in serum potassium levels $(\mathrm{P}<0.01)$ during the phase of experimental hyperaldosteronism.

\section{DISCUSSION}

The results of both acute and chronic studies show that aldosterone had no influence upon gastric acid and pepsin secretion, thus failing to explain the hyposecretion seen in experimental obstruction to hepatic venous outflow and probably that seen in human cirrhotic ascites. However, in the acute infusion studies where a significant change in sodium content of gastric secretion was induced, an effect upon gasti ic electrolyte secretion was seen.

The apparent discrepancy between the results of the acute and chronic studies may be due to an 'escape' mechanism (August, Nelson, and Thorn, 1958) for $\mathrm{Na}^{+}$as occurs in the renal tubules after several days of aldosterone administration, but not with the urinary secretion of $\mathrm{K}^{+}$which continues at the same increased rate. As gastric potassium secretion was unchanged or tended to decrease, this explanation is probably inapplicable to the gastric mucosa. Possibly the rise in $\mathrm{Na}^{+}: \mathrm{K}^{+}$ratios in the gastric juice is a reflection of the changes which occur in the extracellular fluid.

There have been two previous reports on the subject of aldosterone and gastric secretion. Clarke, Neill, and Welbourn (1960) found increased acid concentration in basal and histamine-stimulated secretions and significant falls in basal $\mathrm{Na}^{+}$concentration, histamine-stimulated $\mathrm{K}^{+}$and basal $\mathrm{Cl}^{-}$concentrations. Gilder and Moody (1966) in acute studies assessed the effect of 0.1 and $0.5 \mathrm{mg}$ aldosterone administered intravenously in normal and adrenalectomized Heidenhain pouch dogs. They were unable to demonstrate any significant changes in volume, acid, pepsin, or electrolyte output of gastric juice. The only common finding in these and our own studies is the absence of any influence of aldosterone upon gastric pepsin secretion.

Experimentally, depression of gastric secretion by potassium depletion (Carone and Cooke, 1953; De Muro, Rowinski, Calaresu, and Fraghi, 1961) has been induced with deoxycorticosterone given over one and a half to four weeks. The dosage of aldosterone used in our experiments was relatively much lower. Statistically significant falls in serum $\mathrm{K}^{+}$ levels were observed in all our dogs receiving daily injections of aldosterone, but they were only to the lower limits of normal. It was unlikely that the severe degree of potassium depletion required to reduce gastric secretion was achieved, or indeed, would have been achieved by other than very high dosage.

A further observation, relevant to hyperaldosteronism and gastric secretion, was that of van Buchem, Doorenbos, and Elings (1956), who reported a case of Conn's syndrome due to adrenal hyperplasia, in which histamine-fast achlorhydria was corrected by bilateral adrenalectomy. Though this is suggestive of an aldosterone influence acting upon gastric secretion through potassium deficiency, the findings of Casey, Summerskill, and Orvis (1965) suggest that hyperaldosteronism may not be a major factor in the reduction of body potassium stores in human cirrhosis. Clearly further investigation of gastric secretion in cases of primary and secondary hyperaldosteronism and evaluation of more prolonged experimental administration of the hormone are required. But, from the results of the present study, it does not appear that aldosterone in pathological dosage is a decisive factor in the hyposecretion of human cirrhosis.

\section{SUMMARY}

Acute intravenous infusions of aldosterone and of chronic daily injections of aldosterone in oil administered to a group of Heidenhain pouch dogs had no effect upon gastric acid and pepsin secretion. In the acute studies, gastric sodium secretion was decreased significantly but, in the chronic studies, aldosterone induced statistically significant increases in the sodium : potassium ratios. 
It is concluded that aldosterone probably does not influence acid and pepsin secretion in human or experimental hepatic cirrhosis either by a direct effect on the gastric mucosa or by depletion of body potassium.

Further details of methods and results are available upon request.

The authors wish to express their gratitude to CIBA Laboratories Ltd, Horsham, Sussex, for the generous supply of aldosterone monoacetate in oil. This work was supported by M.R.C. grant G.964/272/C to the first author.

\section{REFERENCES}

August, J. T., Nelson, D. H., and Thorn, G. W. (1958). Response of normal subjects to large amounts of aldosterone. J. clin. Invest., 37, 1549-1555.

Baddeley, R. M. (1968). Gastric secretion in human and experimental cirrhosis. Paper read at Third Cong. Europ. Soc. Exp. Surg., Munich. April 1968.
- -, Nutting, R. O., Ross, T. H., Sloop, R. D., Halasz, N. A., and Orloff, M. J., (1964). Gastric secretion in experimental liver disease. Surg. Forum, 15, 114-116.

van Buchem, F. S. P., Doorenbos, H., and Elings, H. S. (1956). Conn's syndrome caused by adrenocortical hyperplasia. Acta endocr. (Kbh.), 23, 313-330.

Carone, F. A., and Cooke, R. E. (1953). Effect of potassium deficiency on gastric secretion in the rat. Amer. J. Physiol., 172, 684-688.

Casey, T. H., Summerskill, W. H. J., and Orvis, A. L. (1965). Body and serum potassium in liver disease. I. Relationship to hepatic function and associated factors. Gastroenterology, 48, 198-207.

Clarke, S. D., Neill, D. W., and Welbourn, R. B. (1960). The effects of corticotrophin and corticoids on secretion from denervated gastric pouches in dogs. Gut, 1, 36-43.

De Muro, F., Rowinski, P., Calaresu, I., and Fraghi, A. (1961). The importance of potassium in the mechanism of gastric hydrochloric acid secretion. Acta med. scand., 170, 403-410.

Gilder, H., and Moody, F. G. (1966). Aldosterone effect on canine gastric juice. Proc. Soc. exp. Biol. (N.Y.), 121, 913-918.

Orloff, M. J., Ross, T. H., Baddeley, R. M., Nutting, R. O., Spitz, B. R., Sloop, R. D., Neesby, T., and Halasz, N. A. (1964). Experimental ascites. VI. The effects of hepatic venous outflow obstruction and ascites on aldosterone secretion. Surgery, 56, 83-98.

Weast, R. C. (1964). Handbook of Chemistry and Physics, 45th ed. Chemical Rubber Co., Cleveland, Ohio, P.C. 660. 